\title{
TESTE DE MÉTODOS DE INTERPRETAÇÃO GEOQUÍMICA POR COMPUTADOR NA MINA DO PAQUEIRO, ADRIANÓPOLIS, PARANÁ
}

\author{
A.B.Macedo \\ M.A.Braghin \\ F.R.S.Moreira
}

A mina do Paqueiro situa-se no município de Adrianópolis, Paraná. A área é formada por metassedimentos pré-cambrianos do Grupo Açungui e diques básicos mesozóicos. Contém mineralizações de chumbo epigènéticas em rochas carbonáticas, já lavradas em duas áreas (Paqueiro e Bueno).

A prospecção geoquímica foi decisiva para a descoberta da jazida (Damasceno, 1967). Durante o projeto Integração e Detalhe Geológico no Vale do Ribeira (Batolla Jr. et al., 1981) foram coletadas 1009 amostras de solo, analisadas por Absorção Atômica para $\mathrm{Cu}, \mathrm{Pb}$ e $\mathrm{Zn}$, e efetuado levantamento topográfico planialtimétrico de detalhe. Este conjunto de dados de teores e cotas foi escolhido para teste de programas de computador para interpretação geoquímica e geoprocessamento com objetivos práticos (teste e incorporação de técnicas) e didáticas (treinamento do pessoal do projeto e preparação de exercícios de aula). Foram testados os programas PROBPLOT v. 1.0 (Stanley, 1987), GEOEAS v. 1.0 (EPA), SURFER v. 4.0 (Golden Software) e IDRISI v. 4.1 (Clark University).

O programa PROBPLOT permite a detecção de anomalias geoquímicas pela decomposição das distribuições estatísticas dos teores em grupos derivados de subpopulações normais ou lognormais. Ofereceu bons resultados na determinação de limiares de anomalias, utilizados como parâmetros para equidistâncias em mapas de isoteores.

O programa GEOEAS faz gráficos e histogramas, mas não decomposição das distribuições por subpopulações. Tem possibilidades gráficas limitadas, melhor cobertas pelos outros programas.

O programa SURFER é poderoso, simples e relativamente barato, executando bem mapas de contorno e blocos-diagrama, a partir de coordenadas cartesianas tridimensionais.

O IDRISI é um sistema completo para montagem e análise de um Sistema de Informações Georeferenciadas (SIG), simples e muito barato. Permite a execução de mapas, perfis,

Departamento de Geologia Econômica e Geofísica Aplicada, Instituto de Geociências, USP. 
análises estatísticas limitadas e análise por sobreposição de mapas, análise de proximidade e contexto.

Os programas foram testados com os dados geoquímicos da mina do Paqueiro. $O$ programa PROBPLOT deu melhores resultados na determinação de anomalias, as quais só podem ser inferidas no programa GEOEAS por observação visual ou cálculo manual a partir do gráfico de probabilidades. O programa SURFER é bem adequado à produção de mapas de contorno e blocosdiagramas, sendo melhor que o IDRISI para a produção de resultados impressos em impressora pretoe-branco. O IDRISI é mais limitado que o GOLDEN para a produção de mapas de contorno, produz melhores blocos-diagramas quando se dispõe de impressora colorida compatível e tem possibilidades de análises de geoprocessamento impossiveis de ser realizadas pelos outros programas. Pode ser combinado a programas de desenho (Paintbrush, Photostyler) para melhor apresentação de produtos coloridos.

Os resultados das análises confirmam os obtidos por processos manuais por Macedo, in Ferreira et al. (1981). Além da precisão, os resultados obtidos por computador tiverem menor custo e podem ser melhor utilizados para a produção de mapas e relatórios, por sua maior flexibilidade, podendo ser exportados para outros programas e/ou passados para papel por plotters e impressoras preto-e-branco e coloridos.

\section{REFERÊNCIAS BIBLIOGRÁFICAS}

BATOLLA Jr, F. et al. (Coordenador) (1981) Projeto Integração e Detalhe Geológico no Vale do Ribeira - Relatório Final. São Paulo, DNPM/CPRM, 15 v.

FERREIRA, J.C.G.; CHIODI, C.; MACEDO, A.B.; BATOLLA, F. (1981) Área Mina do Paqueiro. Projeto Integração e Detalhe Geológico no Vale do Ribeira - Relatório Final, V. IX. São Paulo, DNPM/CPRM, $117 \mathrm{p}$.

STANLEY, C.R. (1987) PROBPLOT - An interactive computer program to fit mixtures of normal (or log-normal) distributions using maximum likehood optimization procedures. Vancouver, Un. British Columbia, 97p. 